\title{
An indoor mesocosm system to study the effect of climate change on the late winter and spring succession of Baltic Sea phyto- and zooplankton
}

\author{
Ulrich Sommer · Nicole Aberle - Anja Engel - Thomas Hansen • \\ Kathrin Lengfellner $\cdot$ Marcel Sandow $\cdot$ Julia Wohlers · \\ Eckart Zöllner · Ulf Riebesell
}

Received: 7 February 2006/ Accepted: 9 August 2006

(C) Springer-Verlag 2006

\begin{abstract}
An indoor mesocosm system was set up to study the response of phytoplankton and zooplankton spring succession to winter and spring warming of sea surface temperatures. The experimental temperature regimes consisted of the decadal average of the Kiel Bight, Baltic Sea, and three elevated regimes with $2^{\circ} \mathrm{C}$, $4^{\circ} \mathrm{C}$, and $6^{\circ} \mathrm{C}$ temperature difference from that at baseline. While the peak of the phytoplankton spring bloom was accelerated only weakly by increasing temperatures (1.4 days per degree Celsius), the subsequent biomass minimum of phytoplankton was accelerated more strongly (4.25 days per degree Celsius). Phytoplankton size structure showed a pronounced response to warming, with large phytoplankton being more dominant in the cooler mesocosms. The first seasonal ciliate peak was accelerated by 2.1 days per degree Celsius and the second one by 2.0 days per degree Celsius. The overwintering copepod populations declined faster in the warmer mesocosm, and the appearance of nauplii was strongly accelerated by temperature ( 9.2 days per degree Celsius). The strong difference between the acceleration of the phytoplankton peak and the accel-
\end{abstract}

Communicated by Roland Brandl.

Priority programme of the German Research

Foundation- contribution 3 .

U. Sommer $(\bowtie) \cdot$ N. Aberle $\cdot$ T. Hansen · K. Lengfellner

M. Sandow · J. Wohlers · E. Zöllner · U. Riebesell

Leibniz Institute for Marine Sciences, Kiel University,

Düsternbrooker Weg 20, 24105 Kiel, Germany

e-mail: usommer@ifm-geomar.de

A. Engel

Alfred Wegener Institute, Bremerhaven, Germany eration of the nauplii could be one of the "Achilles heels" of pelagic systems subject to climate change, because nauplii are the most starvation-sensitive life cycle stage of copepods and the most important food item of first-feeding fish larvae.

Keywords Plankton $\cdot$ Climate change $\cdot$ Seasonal succession $\cdot$ Spring bloom

\section{Introduction}

Motivation

Climate change is already affecting a wide variety of ecosystems (Walther et al. 2002), including aquatic ones (Edwards et al. 2002; Edwards and Richardson 2004; Fromentin and Planque 1996; Straile 2000; Straile and Adrian 2000), and will increasingly continue to do so if the prevailing predictions of further greenhouse warming are fulfilled. Already, now, the Baltic Sea is characterised by a strong geographic, seasonal, and interannual variability of all relevant hydrographic variables, which are closely connected to the atmospheric forcing in the region (Matthäus and Schinke 1994; Lehmann et al. 2002). Present day interannual differences in surface temperature during winter may amount to $5^{\circ} \mathrm{C}$. Seasonal temperature stratification does not start before April, while reduced salinity stratification persists throughout the winter. Based on the current knowledge [summarised by the International Panel on Climate Change (IPCC) 2001] mainly a pronounced winter warming is expected for northcentral Europe. For a doubling of $\mathrm{CO}_{2}$ emissions during the twenty-first century ("business as usual 
scenario", 192a, HadCM3) an increase of annual mean surface temperatures by $3-5^{\circ} \mathrm{C}$ can be predicted, while winter temperature could increase by even $5-10^{\circ} \mathrm{C}$ (prediction for 2070-2100, compared with the reference period 1960-1990).

It is the ultimate research question of this study: how will the spring succession of plankton change in response to the forecasted climate changes at the beginning of the growth season? Plankton from the Kiel Bight (western Baltic Sea) is intended to serve as a model system for moderately deep water bodies, where the spring bloom of phytoplankton can start before the onset of thermal stratification. This is a pronounced contrast to deep water bodies (e.g. Lake Constance; Scheffer et al. 2001), where there is strong coupling between the light and the temperature, because phytoplankton receive too little light for the onset of spring growth before temperature stratification begins ("critical mixing depth concept" sensu Sverdrup 1953). It is hypothesised that increased temperatures will accelerate heterotrophic processes more strongly than light-limited phytoplankton growth. This should lead to more profound community level changes than to a simple seasonal advancement of events. Different temperature sensitivities of seasonal growth patterns and activity patterns in food webs could lead to a loss in synchrony between prey supply and predator demand with far reaching ecosystem consequences (cf. the "match-mismatch" hypothesis; Cushing 1975).

Traditional field mesocosms would have been a logical choice for the scale of experimentation needed, but temperature control of such systems was beyond our capacity. Therefore, we developed a new type of indoor mesocosm, which combined a plankton container and a benthos container serving as a source for meroplanktonic larvae and benthic resting stages of plankton organisms. The proximate goal of this study was a feasibility test of our experimental systems, concentrating on three questions:

- Are we able to reproduce the natural pattern of plankton spring succession in our mesocosms?

- How long can the mesocosms be operated before containment artefacts become too strong?

- Given the usual variability between replicate mesocosms, will it be possible to obtain statistically significant temperature effects?

\section{Plankton seasonal succession}

According to the predominant paradigm, seasonal succession of plankton is initiated by the spring blooms of autotrophic phytoplankton. In temperate and boreal waters this spring bloom is almost a start from zero, because only few phytoplankton have survived winter. The spring bloom is initiated by the improvement of light supply (for reviews cf. Greve and Reiners 1995; Sommer et al. 1986; Sommer 1996). The direct, physiological consequences of temperature play no prominent role in the initiation of the phytoplankton spring bloom, because of the well-known temperature independence of light-limited photosynthetic rates at temperatures $>2^{\circ} \mathrm{C}$ (Tilzer et al. 1986).

Zooplankton spring growth follows after the phytoplankton spring bloom, the usual sequence being first a bloom of fast-growing protozoans followed by slower growing metazoans. This sequence can be reversed, if there are strong over-wintering mesozooplankton populations (often the case in copepods). After a few weeks of zooplankton increase, grazing rates exceed phytoplankton production and lead to a decline in phytoplankton biomass and a subsequent biomass minimum in late spring/early summer (called "clearwater phase" in the limnological literature). While the causation of the clear-water phase by grazing has been well accepted in limnology for two decades, it is still controversial in biological oceanography (as an example for a grazing-induced clear-water phase see Bautista et al. 1992). Obviously, there are cases where nutrient limitation and subsequent aggregation of phytoplankton lead to major sinking losses prior to the onset of heavy grazing (Smayda 1971; Smetacek et al. 1984).

The spring development of phytoplankton and zooplankton depends differently on physical conditions during early spring: phytoplankton growth depends on light (and stratification in deep waters), while zooplankton growth depends on food availability and temperature. With identical food supply, zooplankton population growth will become faster, the warmer spring temperatures are. This temperature dependence can be accentuated if the spring population depends on the germination of resting stages. Madhudatrap et al. (1996) triggered the germination of six Baltic Sea zooplankton species (four copepods, two cladocerans) by temperature increase in the laboratory. The temperature dependence of zooplankton spring growth must have consequences for the timing and extent of the clear-water phase, as predicted by a recent model for Lake Constance (Scheffer et al. 2001) and by an analysis of field data using the present day climate variability (Straile 2000).

However, those results cannot be simply extrapolated to marine food webs with a more complex mesozooplankton structure, particularly because copepods are not as herbivorous as previously assumed (e.g. 
White 1979). They are omnivores, which feed on protozoans and large phytoplankton, while phytoplankton $<10 \mu \mathrm{m}$ are not taken if there is enough large food (Katechakis et al. 2002; Kleppel 1993; Sell et al. 2001; Sommer and Stibor 2002). This could lead to the following consequences of warming to the spring succession in the Baltic Sea: an earlier onset of calanoid copepod grazing would reduce the biomass of large phytoplankton while releasing small phytoplankton from grazing pressure by protozoans. Thus, phytoplankton size and species composition would change without change of the overall seasonal biomass pattern.

\section{Methods}

\section{Mesocosms}

Eight mesocosms were set up in temperature-controlled culture rooms of the IfM-GEOMAR. The experimental period lasted from 4 February to 4 May in order to encompass the winter-spring transition. The mesocosms consisted of a two-chamber system (Fig. 1), with a 1,400 1 plankton chamber and a smaller (300 l) benthos chamber, which served as a source of meroplanktonic larvae of zoobenthos and of planktonic organisms germinating from benthic resting stages. The plankton was gently stirred by a propeller. The benthos chamber was filled with sediment from the Kiel Fjord and 20 adult blue mussels Mytilus edulis. There was a continuous, but small, exchange (on average ca. 601 , with some variability from 301 to 901 ) of the water between both chambers. This was sufficient for feeding the mussels with phytoplankton but was an insignificant loss for phytoplankton, even if all the phytoplankton would have been consumed by the mussels $(<5 \%$ loss per day). Temperature and light regimes in both chambers were identical. The experiment was run as an almost closed system. Only the sample volume was replaced by unfiltered water from the Kiel Fjord.

\section{Temperature regime}

There were four temperature regimes (each duplicated), defined by the initial temperature difference from the decadal mean 1993-2002 in Kiel Bight, called $0,+2,+4,+6$ treatments. The initial temperature differences between treatments of $2^{\circ} \mathrm{C}$ were maintained until the end of February and were reduced by $0.25^{\circ} \mathrm{C}$ per month thereafter, in order to mimic the less pronounced warming later in the year. Actual temperatures measured in the mesocosms deviated only slightly from planned ones, particularly in one of the $+6^{\circ} \mathrm{C}$ treatments (Fig. 2).

\section{Light regime}

Light was supplied by computer-controlled aquarist light units (GHL Groß Hard- und Softwarelösungen, Lampunit HL3700 and ProfiluxII). Each light unit contained six fluorescent tubes [T5, types $5 \times$ JBL Solar Tropic $(4,000 \mathrm{~K}), 1 \times \mathrm{JBL}$ Solar Natur $(9,000 \mathrm{~K})]$. This setup allowed the simulation of daily triangular light

Fig. 1 Scheme of mesocosms

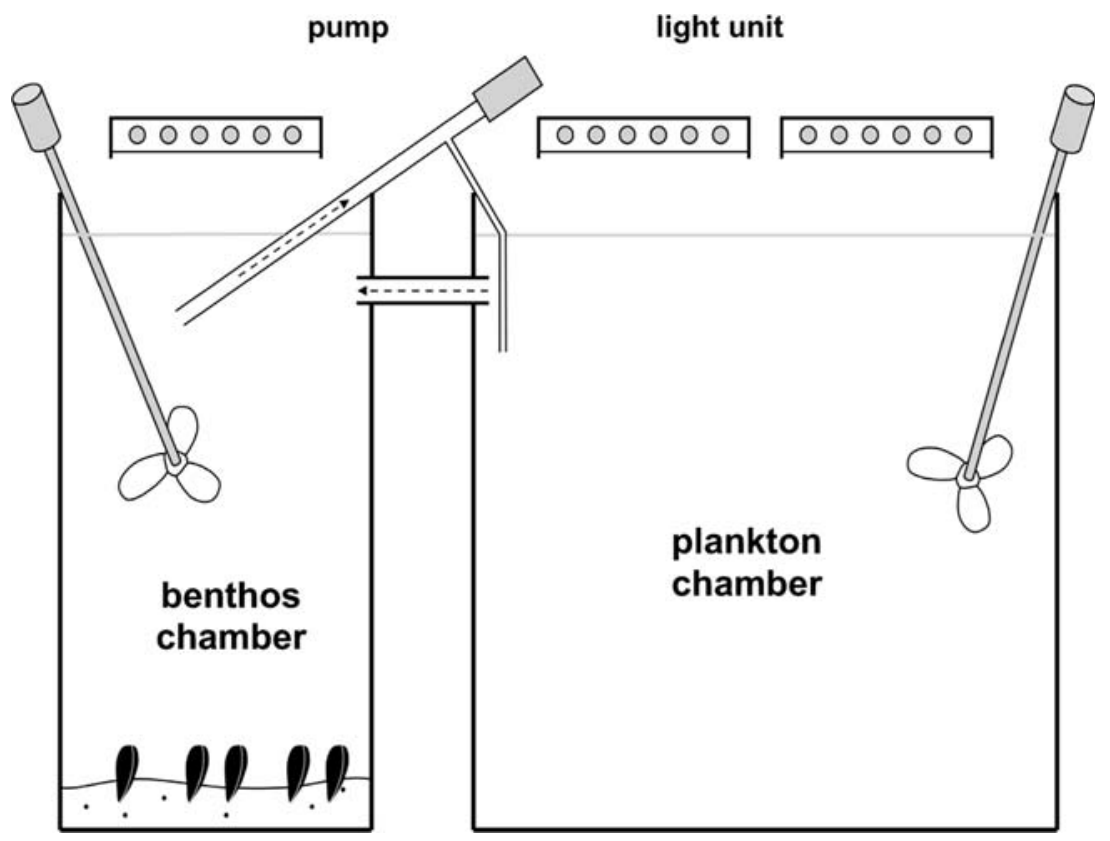




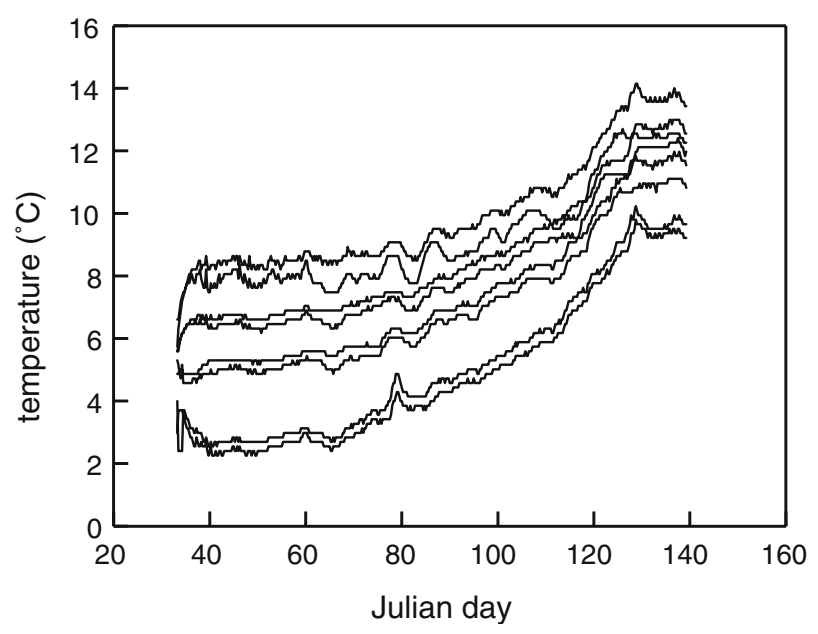

Fig. 2 Temperature regime in the mesocosms

curves. Timing of sunrise and sundown and the maximum light intensity was daily supplied by a specialised database computer program (GHL, Prometeus). Season-dependent database values were derived from a model that is based on astronomic formulae (Brock 1981). The astronomic peak-shaped light curve was transformed into a triangular light curve by calculating sunrise and sundown to preserve daily integrated light intensities. Light attenuation by the cloud cover was superimposed by a randomised cloud cover generator (ProfiluxII), assuming an average $80 \%$ cloud cover. We made a further reduction in light intensity, in order to account for water column light attenuation, by calculating the mean light intensity $\left(I_{\text {mix }}\right)$ of a $12 \mathrm{~m}$ mixed water column ( $\mathrm{z}$; here depth of the halocline) and an average attenuation coefficient $(k)$ of $0.5 \mathrm{~m}^{-1}$ according to the equation of Riley (1957):

$I_{\text {mix }}=I_{0}\left(1-\mathrm{e}^{-k z}\right)(k z)^{-1}$.

Stocking with organisms, and water exchange

Initially, the mesocosms were filled with unfiltered water from Kiel Bight containing the over-wintering populations of phytoplankton, bacteria, and protozoa. Mesozooplankton was added from net catches at natural densities (ca. 20 ind $\mathrm{l}^{-1}$ ) which conforms to usual February values (Behrends 1996). It consisted mainly of the cyclopoid copepod Oithona similis and the calanoid copepod Pseudocalanus/Paracalanus spp.

Copepod survival experiment

From 3 June to 13 July we performed a "copepod survival experiment" in one of the warmest and one of the coldest mesocosms in order to test whether the copepod mortality observed during the main experiment could be explained by containment artefacts, stirring or otherwise unfavourable mechanical conditions. In order to enhance food supply, the experiment was run under high light conditions, i.e. $100 \%$ surface light with the day length of the season.

Samples

Samples for nutrient chemistry, phytoplankton, and protozoa were taken three times per week (Monday, Wednesday, Friday), while samples for mesozooplankton were taken once per week. Phytoplankton and protozoan samples for microscopic counts were fixed with Lugol's iodine, while samples for flow cytometric analysis were processed immediately. Mesozooplankton samples were taken with a bucket (three times $5 \mathrm{l}$, once per week), filtered onto a $64 \mu \mathrm{m}$ sieve and fixed with industrial methylated spirit.

Phytoplankton $>5 \mu \mathrm{m}$ and protozoa were counted by the inverted microscope method (Utermöhl 1958) and distinguished at the genus level in most cases. We aimed at counting 100 individuals per taxonomic unit, which gives $95 \%$ confidence limits of $\pm 20 \%$, but this standard could not be attained with rare species. Small phytoplankton were counted by a flow cytometer (FACScalibur, Becton Dickinson) and distinguished by size and fluorescence of the pigments chlorophyll $a$ and phycoerythrin. Three flow cytometer categories were matched to taxa identified microscopically (the small flagellates Chrysochromulina, Plagioselmis, Teleaulax). Flow cytometry counts were consistently higher than were microscopic ones, indicating incomplete sedimentation in the Utermöhl counting chambers. Phytoplankton cell volumes were calculated from linear measurements after approximation to the nearest geometric standard solid (Hillebrand et al. 1999) and converted into carbon content according to Menden-Deuer and Lessard (2000). Phytoplankton were grouped in four functional categories: autotrophic picoplankton $(<3 \mu \mathrm{m})$, nanoflagellates $(3-20 \mu \mathrm{m})$, nanodiatoms $(3-20 \mu \mathrm{m})$, and microdiatoms $(>20 \mu \mathrm{m})$. Flagellates $>20 \mu \mathrm{m}$ were found occasionally but never exceeded $1 \%$ of total biomass. For ciliate counts the samples were transferred to $100 \mathrm{ml}$ sedimentation chambers, and, for each sample, we counted the whole area of the bottom plate in order to guarantee precise data. For bio-volume calculations geometric proxies were used according to Hillebrand et al. (1999), and ciliate carbon biomass was calculated using the conversion factors given in Putt and Stoecker (1989). 
Mesozooplankton samples were counted with a binocular microscope (Leica MS5). Copepod adults and copepodites were distinguished by genus. Copepod nauplii were not distinguished taxonomically. The rest of the mesozooplankton was separated into larval types (e.g. polychaete larvae, cirripedia larvae, etc.). As the experiment was planned to run for several months we had to keep sample sizes small in order to diminish the mesozooplankton populations as little as possible. Therefore, our samples (three times 51 out of each mesocosm per week) did not contain enough individuals to have similarly high counting standards as for phytoplankton.

Water samples for the determination of inorganic nutrient concentrations were taken after filtration through $0.65 \mu \mathrm{m}$ cellulose acetate filters. The measurements of nitrate, nitrite and phosphate were carried out following the standard protocols by Hansen and Koroleff (1999). Ammonium concentrations were determined from unfiltered samples according to the protocol described by Holmes et al. (1999). All analyses were performed on the day of sampling. Particulate organic carbon (POC) and particulate organic nitrogen (PON), as well as particulate organic phosphorus (POP), were determined from $500 \mathrm{ml}$ samples filtered onto pre-combusted Whatman GF/F filters. After filtration the samples were immediately frozen and stored at $-20^{\circ} \mathrm{C}$. Analysis of POC and PON were carried out by a gas chromatograph after Sharp (1974) on a EuroVector elemental analyser, whereas the measurement of POP was conducted colorimetrically after oxidation with potassium peroxodisulphate, as described by Hansen and Koroleff (1999). Samples for particulate nutrients were not measured before the beginning of the phytoplankton spring bloom.

\section{Results}

Phytoplankton

Initially, phytoplankton biomass declined until Julian days 54-63. The decrease was steeper in the warmer treatments (Fig. 3). Thereafter, phytoplankton biomass increased to form a spring bloom. The timing of the
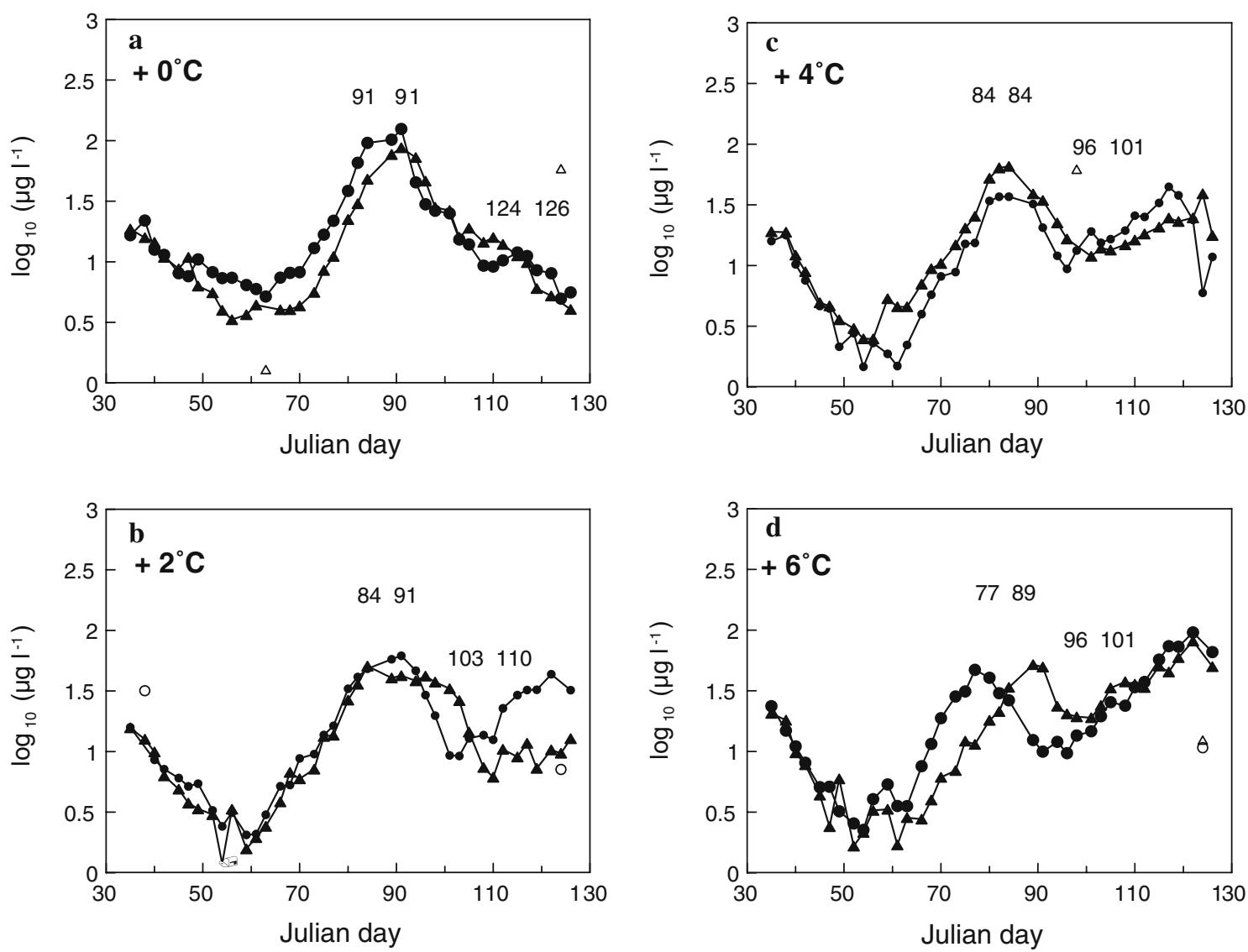

Fig. 3 Phytoplankton biomass $\left(\mu \mathrm{g} \mathrm{C}{ }^{-1}\right)$ in the mesocosms. Numbers indicate day of spring bloom (biomass maximum) and clearwater phase (biomass minimum); treatments: $\mathbf{a}+0^{\circ} \mathrm{C}, \mathbf{b}+2^{\circ} \mathrm{C}, \mathbf{c}+4^{\circ} \mathrm{C}, \mathbf{d}+6^{\circ} \mathrm{C}$ 
spring bloom showed a slight tendency of acceleration by temperature, which was marginally insignificant:

$t_{\mathrm{sp}}=90.5-1.4 \Delta T ; \quad r^{2}=0.43 ; \quad P=0.075$,

where $t_{\mathrm{sp}}$ is the time of the spring phytoplankton maximum (in Julian days) and $\Delta T$ the maximal temperature difference from the baseline treatment. The temperature effect on the time of the clear-water phase $\left(t_{\mathrm{cw}}\right.$, defined by the biomass minimum after the spring bloom) was stronger

$t_{\mathrm{cw}}=119-4.25 \Delta T ; \quad r^{2}=0.80 ; \quad P=0.0025$.

The magnitude of the spring bloom (biomass maximum in $\mu \mathrm{g} \mathrm{C}^{-1}$ ) was negatively correlated to temperature:

$\log ^{10} \mathrm{~B}_{\max }=1.94-0.051 \Delta T ; \quad r^{2}=0.55 ; \quad P=0.0355$

In contrast, minimal biomasses during the clear-water phase were higher at higher temperatures:

$\log _{10} B_{\min }=0.75-0.066 \Delta T ; \quad r^{2}=0.71 ; \quad P=0.0082$

While timing and biomass of the spring bloom were only slightly affected by the temperature increase, there was a strong effect on taxonomic composition. Already during the decline phase, phytoplankton composition had started to diverge. During the pre-bloom minimum, microplanktonic diatoms were dominant in the +0 treatments, while nanoflagellates dominated in the warmer ones. The relative biomass of picophytoplankton also increased with temperature. During the clearwater phase, these trends vanished. Only a unimodal response of picophytoplankton to temperature could be observed. The same compositional trend could be observed at the top of the spring bloom. The statistical significance of compositional trends was tested by a second-order polynomial regression analysis of the arc sine-square root transformed relative biomass values of functional groups $\left[\operatorname{asin} \sqrt{ }\left(B_{\text {group }} / B_{\text {tot }}\right)\right]$ on $\Delta T$. Except for the nanoplanktonic diatoms, all functional groups showed significant trends $(P<0.05)$ during the prebloom minimum and during the spring bloom, while, during the clear-water phase, only the picophytoplankton showed a significant trend (Fig. 4; Table 1).

\section{Ciliates}

At the beginning of the experiment the carbon biomass of ciliates increased in mean within Julian day 50 at the warmest temperature, until day 53 at intermediate
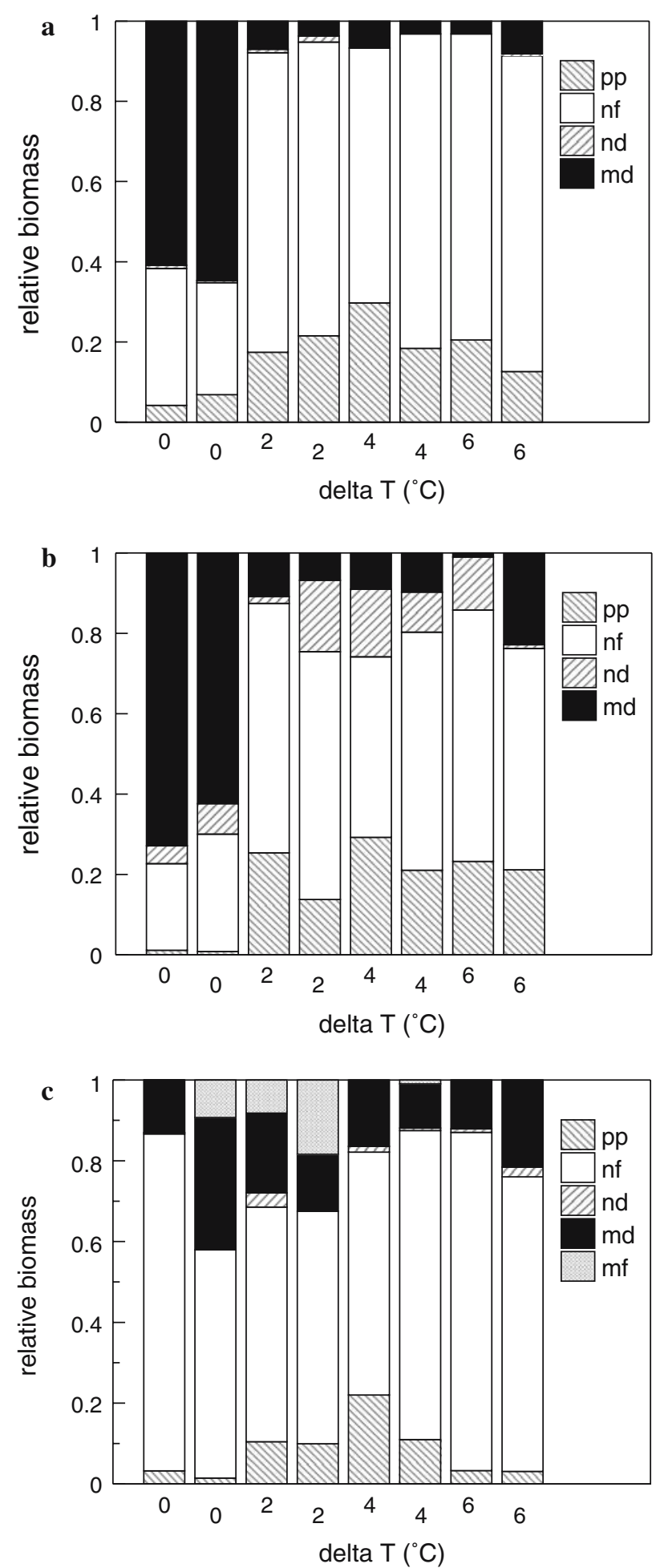

Fig. 4 Relative composition of phytoplankton biomass during the pre-spring bloom minimum, the spring bloom maximum, and the clear-water phase; $p p$ picoplankton, $n f$ nanoflagellates, $n d$ nanodiatoms, $m d$ microdiatoms, $m f$ microflagellates

temperature and until day 65 at the coldest temperature. The timing of biomass increase showed a significant acceleration by temperature (Fig. 5): 
Table 1 Polynomial regressions of the relative biomass of phytoplankton functional groups on experimental warming according to the model $\operatorname{asin} \sqrt{ }\left(B_{\text {group }}\right)$ $\left.B_{\text {tot }}=a+b \Delta T+c \Delta T^{2}\right)$

\begin{tabular}{|c|c|c|c|c|c|}
\hline Functional group & $a$ & $b$ & $c$ & $r^{2}$ & $P$ \\
\hline \multicolumn{6}{|l|}{ Pre-bloom minimum } \\
\hline Picophytoplankton & 12.9 & 7.6 & -0.8 & 0.81 & 0.007 \\
\hline Nanoflagellates & 29.1 & 16.3 & -1.96 & 0.72 & 0.018 \\
\hline Nanodiatoms & \multicolumn{5}{|c|}{ Not significant } \\
\hline Microdiatoms & 54.8 & -21.6 & 2.3 & 0.84 & 0.0034 \\
\hline \multicolumn{6}{|l|}{ Spring bloom } \\
\hline Picophytoplankton & 6.2 & 11.9 & -1.4 & 0.92 & 0.0017 \\
\hline Nanoflagellates & 32.0 & 9.4 & -1.1 & 0.58 & 0.0494 \\
\hline Nanodiatoms & \multicolumn{5}{|c|}{ Not significant } \\
\hline Microdiatoms & 53.4 & -19.8 & 2.35 & 0.74 & 0.0145 \\
\hline \multicolumn{6}{|l|}{ Clear-water phase } \\
\hline Picophytoplankton & 8.4 & 9.6 & -1.54 & 0.80 & 0.0073 \\
\hline Nanoflagellates & Not & & & & \\
\hline Nanodiatoms & Not & & & & \\
\hline Microdiatoms & Not & & & & \\
\hline
\end{tabular}
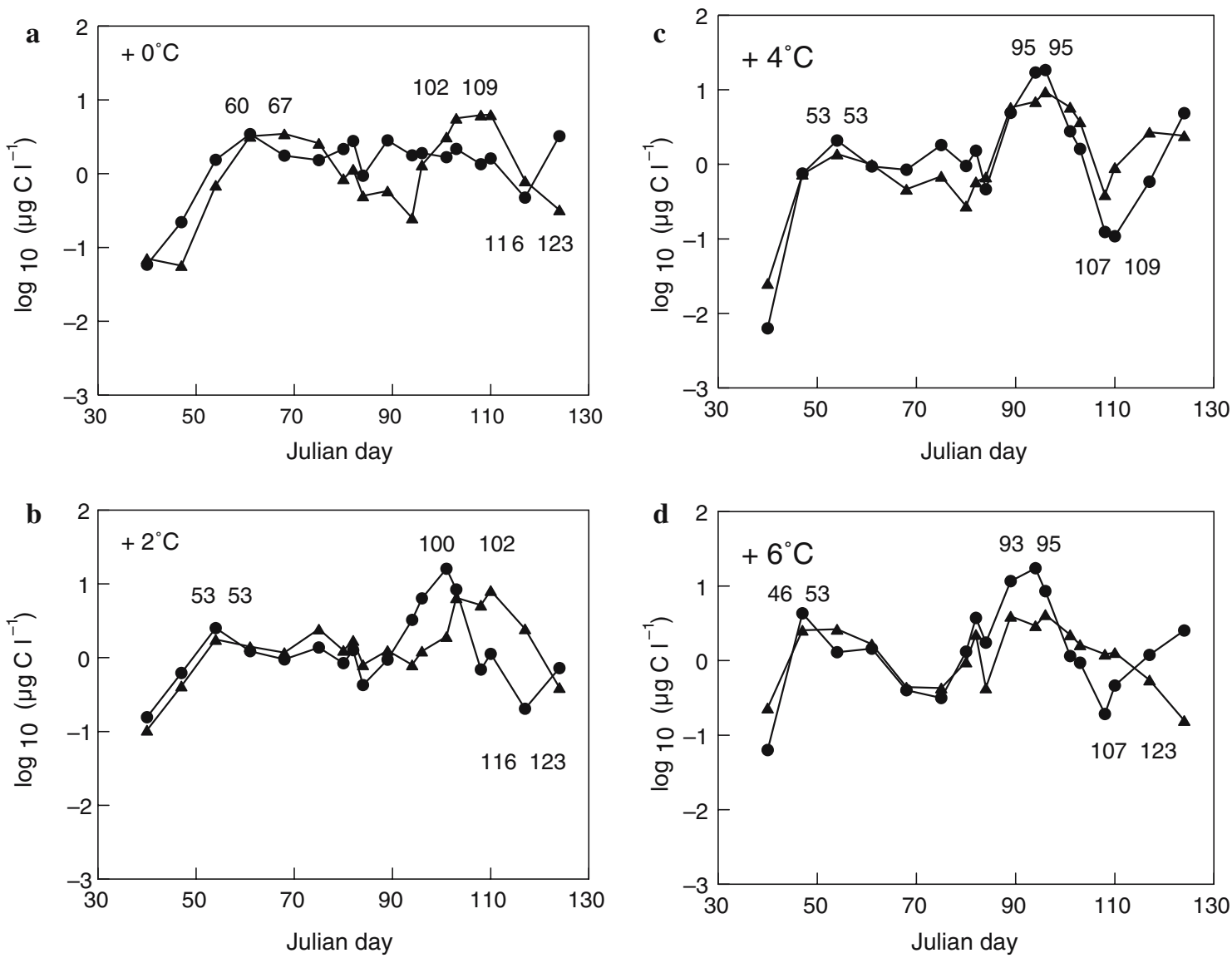

Fig. 5 Ciliate biomass $\left(\mu \mathrm{g} \mathrm{C} 1^{-1}\right)$ in the mesocosms. Numbers indicate day of pre-spring bloom, spring bloom and biomass minimum after spring bloom; treatments: $\mathbf{a}+0^{\circ} \mathrm{C}, \mathbf{b}+2^{\circ} \mathrm{C}, \mathbf{c}+4^{\circ} \mathrm{C}, \mathbf{d}+6^{\circ} \mathrm{C}$

$t_{\mathrm{pscm}}=62-2.1 \Delta T ; \quad r^{2}=0.65 ; \quad P=0.015$,

where $t_{\mathrm{pscm}}$ is the time of the pre-spring bloom ciliate maximum (in Julian days) and $\Delta T$ the maximum temperature difference from that of the baseline treatment.

Thereafter, a decline in protozoan abundance was detected, followed by a transition phase characterised by fluctuating biomass. With the onset of the spring bloom, a significant increase in protozoan biomass was detected, which was, again, accelerated by temperature:

$t_{\mathrm{scm}}=106-2.0 \Delta T ; \quad r^{2}=0.81 ; \quad P=0.0024$,

where $t_{\mathrm{scm}}$ is the time of the spring bloom ciliate maximum. 
The abundance peak maxima were followed by a sharp decline within a few days, and minimum abundances were observed within Julian days 107-123.

\section{Mesozooplankton}

At the beginning of the experiment, the mesozooplankton community consisted of copepods (adults and copepodites; Oithona, Pseudocalanus, Paracalanus, Centropages, Temora) and meroplanktonic larvae from various benthic taxa (polychaetes, mussels, gastropods and cirripedia). Copepods clearly dominated the mesozooplankton community throughout the experiment, providing $>90 \%$ of the overall abundance. All meroplanktonic larvae groups decreased continuously during the course of the experiment, indicating that no further larvae were released from the benthos chamber. The over-wintering copepod generations also decreased, but the appearance of nauplii indicated that they had become reproductive (Fig. 6).

For the analysis of temperature effects the copepods were split into two groups, one containing all nauplius stages and the other all copepodite and adult stages
(CI-CVI). We investigated the decline in the numbers of adults and copepodites by calculating growth rates as the slope of a linear regression of $\ln \mathrm{N}$ on time. Regression analysis for the first 11 weeks of experiment revealed a faster decline of the adult/copepodite group at warmer temperatures. This trend was only of low statistical significance $(P=0.03)$; however, it becomes more obvious if the time period of regression is split into a time period before the spring bloom (Julian days 35-68) and a time period during and after the spring bloom (Julian days 68-103). While there was no correlation for the time period before the spring bloom, growth rates were significantly more negatively affected by elevated temperatures during and after the spring bloom:

$r_{\mathrm{c}}=0.02-0.01 \Delta T ; \quad r^{2}=0.71 ; \quad P=0.008$

where $r_{\mathrm{c}}$ is the growth rate and $\Delta T$ the maximum temperature difference from that of the baseline treatment.

There was a strong acceleration of nauplius production by increasing temperature, as measured by the
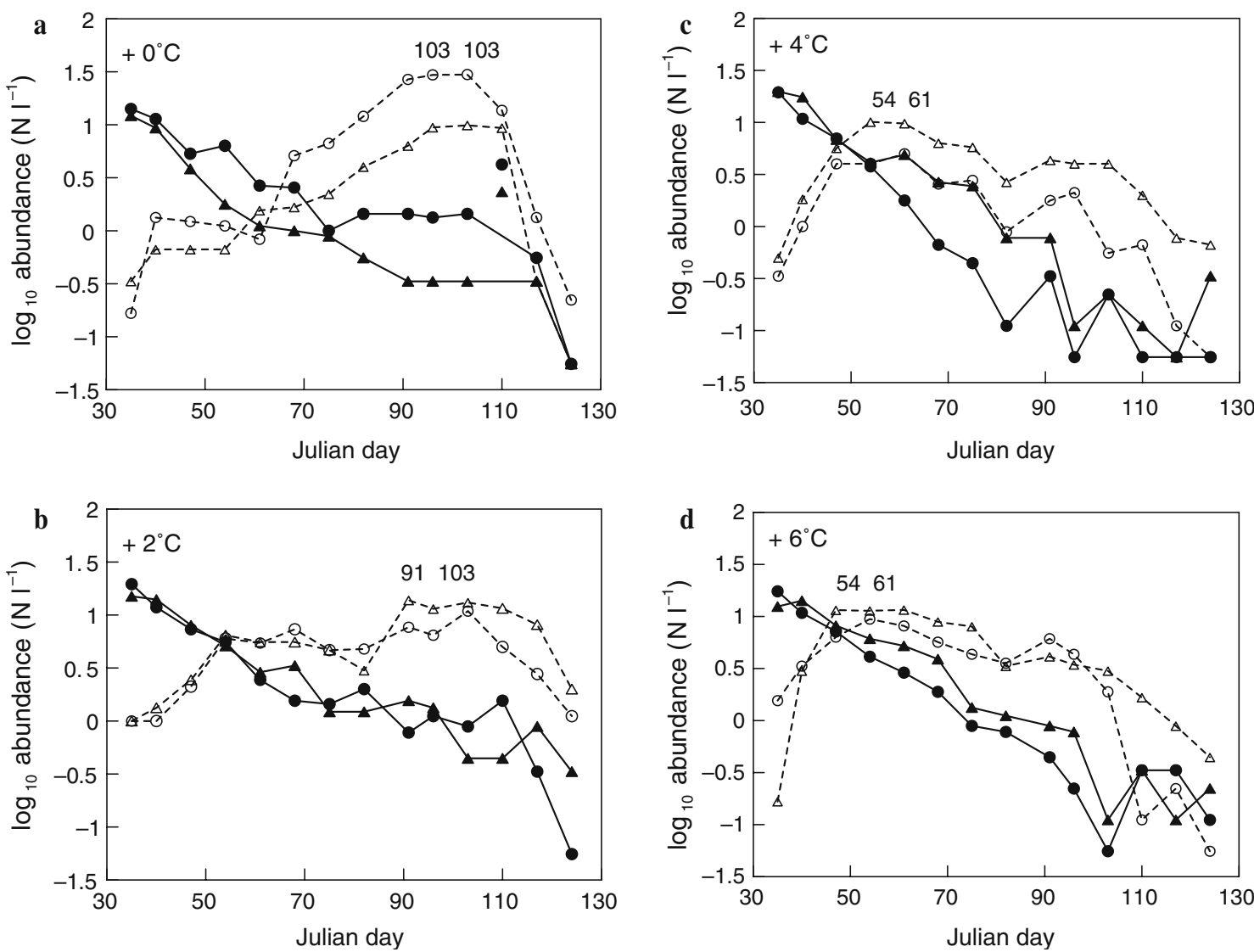

Fig. 6 Copepod abundance $\left(\mathrm{N}^{-1}\right)$ in the mesocosms. Continuous lines and solid symbols indicate adults plus copepodites, broken lines and open symbols indicate nauplii; treatments: $\mathbf{a}+0^{\circ} \mathrm{C}, \mathbf{b}+2^{\circ} \mathrm{C}, \mathbf{c}+4^{\circ} \mathrm{C}, \mathbf{d}+6^{\circ} \mathrm{C}$ 
time of their peak abundance in the different mesocosms:

$t_{\mathrm{nm}}=104.5-9.2 \Delta T ; \quad r^{2}=0.75 ; \quad P<0.0001$.

\section{Nutrient regime}

Dissolved-nutrient concentrations started to decline at the onset of the spring bloom. The concentrations of dissolved phosphate fell to or below the detection limit $\left(0.05 \mu \mathrm{mol} \mathrm{l}^{-1}\right)$ on Julian days 87-91 (no temperaturerelated trend) and remained at that level until the end of the experiment. The concentrations of dissolved nitrate remained well above detection and did not usually fall below $5 \mu \mathrm{mol} \mathrm{l}^{-1}$. C:P ratios in the particulate matter were used as an index of phosphorus limitation of phytoplankton growth (Goldman et al. 1979), with ratios strongly above the Redfield ratio (106:1) being an indication of nutrient-limited conditions. While there was a general increase of C:P ratios during the spring bloom, no decrease was found during the subsequent clear-water phase (Fig. 7). Overall, there was a slight tendency of nutrient limitation to be stronger (higher C:P ratios) in the colder mesocosms:

$\log ^{10}(\mathrm{C}: \mathrm{P})_{\text {mean }}=2.25-0.017 \Delta T ; r^{2}=0.52 ; P \leq 0.0434$,

where $(\mathrm{C}: \mathrm{P})_{\text {mean }}$ was calculated as the geometric mean for the period from day 68 (beginning of spring bloom) to day 110 (end of nutrient measurements).

\section{Discussion}

Feasibility of the experimental system

Overall, the mesocosm system has proven to be a useful tool to study the impact of climate change on the spring succession of plankton in the Kiel Fjord. It was possible to produce the typical pattern of in situ succession, with a spring bloom of phytoplankton, a subsequent clearwater phase (Sommer et al. 1986; Sommer 1996, Greve and Reiners 1995), a biomass increase of ciliates, a
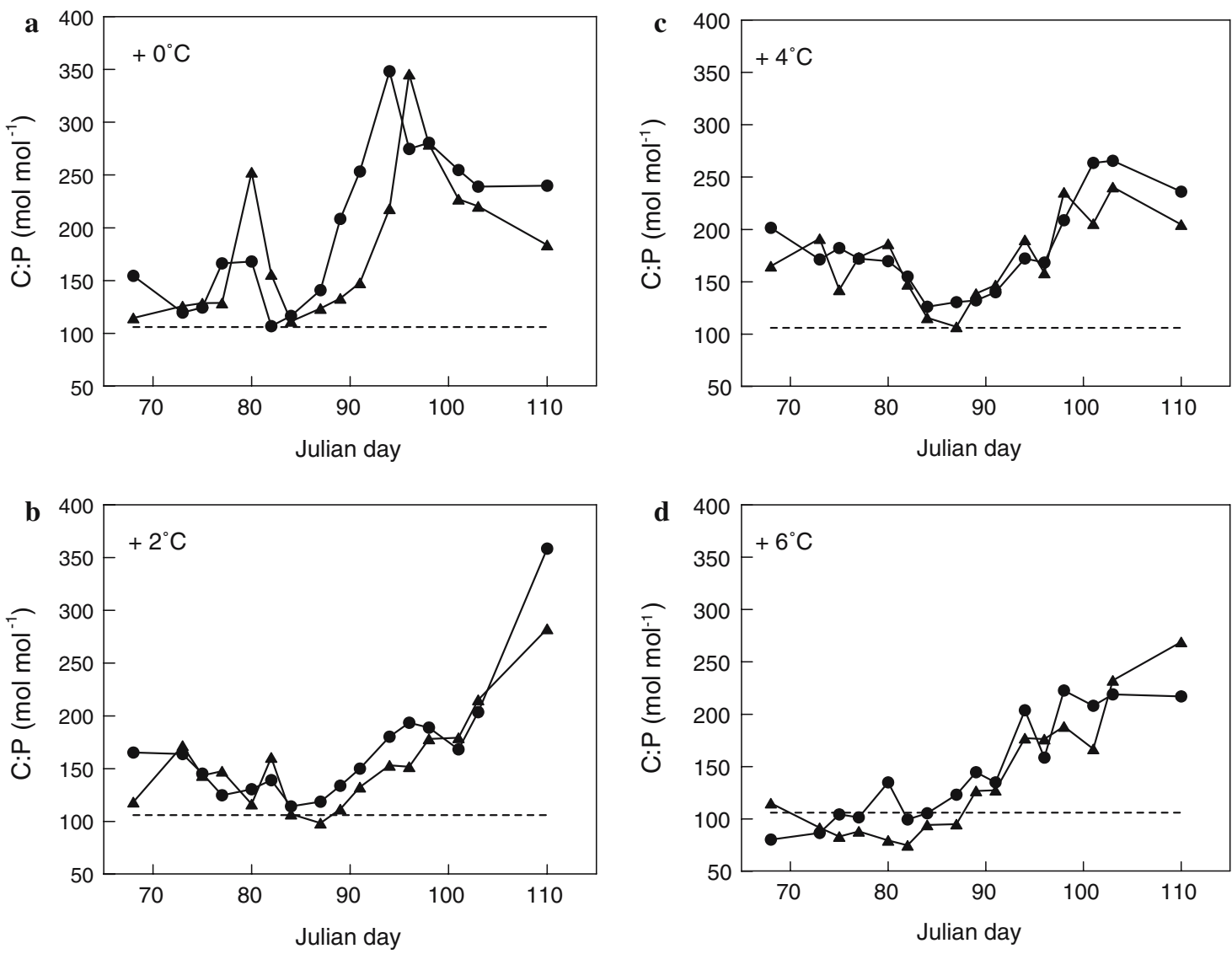

Fig. $7 \mathrm{C}: \mathrm{P}$ ratio in the particulate matter. Horizontal line Redfield ratio (106:1); treatments: $\mathbf{a}+0^{\circ} \mathrm{C}, \mathbf{b}+2^{\circ} \mathrm{C}, \mathbf{c}+4^{\circ} \mathrm{C}, \mathbf{d}+6^{\circ} \mathrm{C}$ 
decline of the over-wintering copepod population and the production of nauplii of the new copepod generations in spring (Behrends 1996). The phytoplankton species lists of the mesocosms showed $>90 \%$ overlap with the species lists from in situ during most of the time. While there was considerable variability between parallel mesocosms, the overall treatment effects were strong enough to produce statistically significant relationships between most biological response variables and temperature elevation.

We can also be confident that the mechanical conditions (stirring, contact with container walls) in our experimental system did not have an adverse mechanical impact on the living conditions on one of the major players in the system, in spite of the observed copepod mortality rates. First, because during the copepod survival experiment (3 June to 13 July), copepod mortality rates were zero. Mechanical conditions were the same as in the main experiment, but food supply was abundant (POC of edible microplankton was always $\left.>10 \mu \mathrm{g} \mathrm{l}^{-1}\right)$. Second, because the rates at which copepod declined during the main experiment were within the same range as those reported by Behrends (1996). Her mean monthly values give the following negative growth rates for February to March: Paracalanus -0.06 per day, Pseudocalanus 0.02 per day, Oithona -0.04 per day. In situ, the beginning growth of the late spring/early summer generation of copepods is usually observed in May and reaches its peak in June (Behrends 1996). The beginning denaturation of our experiment by wall growth (see below) precluded such a long extension of our experiment. However, in the warmer mesocosms, the nauplii obviously failed to develop further into copepodites, clearly before significant wall growth was observed. A closer inspection of the peak dates of nauplii in the warmer treatments showed that they coincided with the period of extremely low phytoplankton biomass. In the coldest treatments the decline of the nauplii occurred towards the end of the experiment, when phytoplankton biomass levels were low as well ("clear-water phase"). We conclude that food shortage was the most probable cause of both adult and nauplius mortality.

The most important deviation from natural conditions was caused by the development of a wall growth by benthic microalgae that increased with time. While this wall growth did not lead to unnatural successional patterns of plankton until the onset of the clear-water phase, it posed a difficulty for mass balances of carbon and nutrients. In addition, trapping of the nutrients in the wall growth might have delayed the recovery of phytoplankton from the clear-water phase and thus enhanced food shortage of zooplankton. Resuspended benthic microalgal species began to appear in the pelagic after Julian day 80 and to exceed $10 \%$ of phytoplankton biomass after Julian days 85-90 (50-55 days after the start of the experiment). We consider this a critical limit and will plan future experiments for a maximum duration of 7-8 weeks.

Temporal restriction is the most serious limitation of the mesocosm approach, because it does exclude the direct study of how changes at the start of the growth season influence the plankton development later in the year. Similarly, long-term responses to climate change (establishment of invading species, evolutionary adaptation of resident species) are beyond the scope of mesocosm experiments. On the other hand, mesocosm experiments form a necessary link between small-scale laboratory experiments with organisms from cultures ("microcosms") and comparative field studies exploiting present day climate variability. In microcosms each functional group is represented by a much smaller species number and responses of functional differences cannot be dampened by interspecific differences in response patterns to temperature or indirect effects ("insurance effect of biodiversity"; Yachi and Loreau 1999). and, thus, potential mismatch effects would be exaggerated. A comparative analysis of field data cannot exceed the current range of climate fluctuations if they are restricted to one site. If comparisons with sites from other climatic zones are included, the influence of confounding factors becomes almost incontrollable. Moreover, at least the role of invasive species can also be studied by mesocosms of our type if there is a priori knowledge about potential candidate species.

\section{Succession patterns}

The succession patterns observed in our experiments differ considerably from the freshwater ones dominated by the zooplankton genus Daphnia spp., analysed in a comparative field study (Straile 2000) and in a model study (Scheffer et al. 2001). In the Daphnia systems seasonal succession starts with close-to-zero levels of both phyto- and zooplankton. Both are physically controlled (light, stratification, temperature) during their initial growth phase, and top-down (grazing) control of phytoplankton does not start before high Daphnia densities are reached towards the end of the spring bloom.

In our system top-down control of phytoplankton appeared to operate from the beginning. Copepod densities were high in the beginning and conformed to natural densities. The subsequent decline was 
accompanied by an increase in ciliate biomass. Phytoplankton reproductive rates had to overcome grazing pressure by both components before the spring bloom could develop. Interestingly, the phytoplankton composition of the spring bloom was already preformed during the initial decline phase, when copepod densities were still high. While we cannot rule out other explanations at present, the pattern observed looked like a strong imprint of zooplankton grazing at higher temperatures. It has been shown in summer experiments that copepod grazing primarily reduces large phytoplankton, while small phytoplankton is at times even favoured, because they are released from ciliate grazing pressure (Feuchtmayr 2004; Granéli and Turner 2002; Sommer et al. 2003a, b, 2005a, b). Contrary to summer conditions, when ciliates preferentially feed on small phytoplankton (Sommer et al. 2005b), the ciliates in our experiment had also fed on large algae (Aberle et al. 2006), which is quite typical for the start of the seasonal growth cycle (Montagnes et al. 1988). Thus, ciliates could maintain the grazing pressure on large phytoplankton even after copepods had declined to population levels ineffective for top-down control. Note, that the between-treatment differences in phytoplankton size spectra had already been established during the initial phase of the experiment, when copepods were still abundant (Fig. 4). Their maintenance until the spring peak can be explained by the ciliates, which had, meanwhile, increased parallel with the copepod decline. While the small differences in zooplankton density between the different temperature treatments probably cannot explain the observed difference between the coldest and the warmer treatments, increased grazing rates at warmer temperatures seems a possible explanation for the more rapid decline of large phytoplankton in the warmer mesocosms. The positive correlation of copepod mortality rates with temperature during and shortly after the spring bloom can most easily be explained by a combination of higher metabolic demands and a more depleted food source at higher temperature.

While food biomass was obviously a highly important bottom-up factor, particularly for copepod survival and the development of nauplii, food nutrient content seemed less important. C:P ratios indicated moderate $\mathrm{P}$ limitation during the spring bloom and towards the end of the experiment, when a substantial amount of the $\mathrm{P}$ was trapped in the wall growth, while zthere was never an indication of $\mathrm{N}$ limitation. Under in situ conditions, the identity of the limiting nutrient varies both between and within years and is strongly dependent on the wind-dependent advection of different water bodies (personal observation). C:P ratios in the range of 300:1 indicate phytoplankton growth rates of ca. $30-70 \%$ of the nutrient-saturated maximum (Goldman et al. 1979; Sommer 1991) if other factors (e.g. light) impose no stronger limitation. They probably do not indicate that phytoplankton is short in $\mathrm{P}$ as a food source for the prevailing mesozooplankton. For the extremely P-demanding Daphnia spp. a C:P ratio of ca. 300:1 is usually assumed as a threshold value for $\mathrm{P}$ limitation, while this threshold must be much higher for the less P-demanding copepods (Urabe et al. 1997; Sterner and Elser 2002).

Overall, our prediction was confirmed: that warming does not only lead to a simple acceleration of otherwise identical succession patterns. There was a modest, though significant, restructuring of the planktonic food web, most conspicuously evident in the dominance of a short, direct food chain (large diatoms $\rightarrow$ copepods) in the coldest treatment and longer food chains in the warmer ones. Nano- and picophytoplankton cannot be consumed by copepods and were apparently also not consumed by ciliates in this case (Aberle et al. 2006). Thus, an additional link (heterotrophic nanoflagellates) is needed to transfer matter and energy from the primary producers to the copepods.

The different shifts of temporal "cardinal points" (phytoplankton spring peak, clear-water phase, ciliate peaks, and nauplius peak) suggest different temperature sensitivities of the underlying processes. The biggest difference in the responsiveness to temperature was found between the peak of phytoplankton biomass (1.4 days per degree Celsius; i.e. 8.4 days over the entire range of experimental conditions) and the peak of nauplii ( 9.2 days per degree Celsius; i.e. 55 days over the entire temperature range). This could be one of the "Achilles heels" of a pelagic system confronted with climate change. First, as early juvenile stages, nauplii are the most starvation-sensitive and the most herbivorous stage of the copepod life cycle (Lopez 1996; Irigoien et al. 2003). This can easily explain the early decline of nauplii in the warm treatments. Second, nauplii are the most important food item of firstfeeding fish larvae which are also the most starvationsensitive life cycle stage of their species (cf. the matchmismatch hypothesis; Cushing 1975). Central questions for the future use of our experimental setup concern the roles of light and over-wintering zooplankton:

Can the phytoplankton spring bloom be accelerated by higher light intensities (i.e. lower cloud cover)?

Does the temperature response of succession patterns depend on light, e.g. because light-saturated photosynthesis is temperature dependent, as opposed to light-limited photosynthesis. 
Does the density of over-wintering zooplankton influence the climate sensitivity of spring succession? Is the over-wintering success itself climate dependent?

Will invasive species dampen or amplify the effect of climate change?

Acknowledgements This work was supported by the DFG (Deutsche Forschungsgemeinschaft) within the priority program 1162 "AQUASHIFT" (The impact of climate variability on aquatic ecosystems). Constructive comments by Herwig Stibor and one anonymous reviewer are gratefully acknowledged.

\section{References}

Aberle N, Lengfellner K, Sommer U (2006) Spring bloom succession, grazing impact and herbivore selectivity of ciliate communities in response to winter warming. Oecologia (this issue)

Bautista B, Harris RP, Tranter PRG, Harbour D (1992) In situ copepod feeding and grazing rates during a spring bloom dominated by Phaeocystis sp. in the English Channel. J Plankton Res 14:691-703

Behrends G (1996) Long-term investigation of seasonal mesozooplankton dynamics in Kiel Bight, Germany. In: Proceedings of the 13th symposium on Baltic and Marine Biology, pp 93-98

Brock TD (1981) Calculating solar radiation for ecological studies. Ecol Model 14:1-19

Cushing DH (1975) Marine ecology and fisheries. Cambridge University Press, Cambridge

Edwards M, Beaugrand G, Reid PC, Rowden AA, Joes MB (2002) Ocean climate anomalies and the ecology of the North Sea. Mar Ecol Progr Ser 239:1-10

Edwards M, Richardson AJ (2004) Impact of climate change on marine pelagic phenology and trophic mismatch. Nature 430:881-884

Feuchtmayr H (2004) Mesozooplankton impacts on lower trophic levels from freshwater, marine and brackish systems in spring - a comparative study. $\mathrm{PhD}$ thesis, University of Kiel

Fromentin JM, Planque B (1996) Calanus and the environment in the eastern North Atlantic. II: Influence of the North Atlantic Oscillation on C. finnmarchicus and C. helgolandicus. Mar Ecol Progr Ser 134:111-118

Goldman JC, McCarthy JJ, Peavey DG (1979) Growth rate influence on the chemical composition of phytoplankton in oceanic waters. Nature 279:210-215

Granéli E, Turner JT (2002) Top-down regulation in ctenophore-copepod-ciliate-diatom-phytoflagellate communities in coastal waters: a mesocosm study. Mar Ecol Progr Ser 239:57-68

Greve W, Reiners F (1995) Biocoenotic process patterns in the German Bight. In: Eleftheriou A, et al (eds) Biology and ecology of shallow coastal waters. Olsen \& Olsen, Fredensborg, pp 67-71

Hansen HP, Koroleff F (1999) Determination of nutrients. In: Grasshoff K, Kremling K, Ehrhardt M (eds) Methods of seawater analysis, 3rd edition. Wiley $\mathrm{VCH}$, Weinheim pp $159-228$

Hillebrand H, Dürselen CD, Kischtel D, Pollingher U (1999) Biovolume calculations for pelagic and benthic microalgae. J Phycol 35:403-424
Holmes RM, Aminot A, Kérouel R, Hooker BA, Peterson BJ (1999) A simple and precise method for measuring ammonium in marine and freshwater ecosystems. Can J Fish Aquat Sci 56:1801-1808

International Panel on Climate Change (IPCC) (2001) Climate change 2001: impacts, adaptations and vulnerability. UNEP and WHO, 2001

Irigoien X, Titelman J, Harris RP, Harbour D, Castellani C (2003) Feeding of Calanus finnmarchicus nauplii in the Irminger Sea. Mar Ecol Progr Ser 262:193-200

Katechakis A, Stibor H, Sommer U, Hansen T (2002) Changes in the phytoplankton community and microbial food web of Blanes Bay (Catalan Sea, NW Mediterranean) under prolonged grazing pressure by doliolids (Tunicata), cladocerans or copepods (Crustacea). Mar Ecol Progr Ser 234:55-69

Kleppel GS (1993) On the diet of calanoid copepods. Mar Ecol Progr Ser 99:183-195

Lehmann A, Krauss WW, Hinrichsen HH (2002) Effects of remote and local atmospheric forcing on circulation and upwelling in the Baltic Sea. Tellus 54A:299-316

Lopez MDG (1996) Effect of starvation on development and survivorship of nauplian Calanus pacificus (Brodsky). J Exp Mar Biol Ecol 203:133-146

Madhudatrap M, Nehring S, Lenz J (1996) Resting eggs of zooplankton (Copepoda and Cladocera) from the Kiel Bay and adjacent waters (southwestern Baltic). Mar Biol 125:77-87

Matthäus W., H. Schinke (1994) Mean atmospheric circulation patterns associated with Major Baltic Inflows. Dt Hydrogr Z 46:321-338

Menden-Deuer S, Lessard EJ (2000) Carbon to volume relationships in dinoflagellates, diatoms and other protist plankton. Limnol Oceanogr 45:569-579

Montagnes DJS, Lynn DH, Roff JC, Taylor WD (1988) The annual cycle of heterotrophic planktonic ciliates in the waters surrounding the Isles of Shoals, Gulf of Maine: an assessment of their trophic role. Mar Biol 99:21-30

Putt M, Stoecker DK (1989) An experimentally determined carbon:volume ratio for marine "oligotrichous" ciliates from estuarine and coastal waters. Limnol Oceanogr 34:1097-1103

Riley GA (1957) Phytoplankton of the North Central Sargasso Sea. Limnol Oceanogr 2:252-270

Scheffer M, Straile D, van Nes EH, Hosper H (2001) Climate warming causes regime shifts in lake food webs. Limnol Oceanogr 46:1780-1783

Sell AF, van Keuren D, Madin LP (2001) Predation by omnivorous copepods on early developmental stages of Calanus finnmarchicus and Pseudocalanus spp. Limnol Oceanogr 46:953-959

Sharp JH (1974) Improved analysis for particulate organic carbon and nitrogen from seawater. Limnol Oceanogr 19:984-989

Smayda TJ (1971) Normal and accelerated sinking of diatoms in the sea. Mar Geol 11:105-122

Smetacek V, v Bodungen B, Knoppers B, Peinert R, Pollehne F, Stegmann P, Zeitszschel B (1984) Seasonal stages characterizing the annual cycle of an inshore pelagic ecosystem. Rapp P V Reun Cons Int Explor Mer 183:126-135

Sommer U (1991) The application of the Droop model of nutrient limitation to natural phytoplankton. Verh Int Verein Limnol 24:791-794

Sommer U (1996) Plankton ecology: the last two decades of progress. Naturwiss 83:393-301

Sommer U, Stibor H (2002) Copepoda-Cladocera-Tunicata: the role of three major mesozooplankton groups in pelagic food webs. Ecol Res 17:161-174 
Sommer U, Gliwicz ZM, Lampert W, Duncan A (1986) The PEG model of seasonal succession of planktonic events in fresh waters. Arch Hydrobiol 106:433-471

Sommer F, Hansen T, Feuchtmayr H, Santer B, Tokle N, Sommer U (2003a) Do calanoid copepods suppress appendicularians in the coastal ocean? J Plankton Res 25:869-871

Sommer U, Sommer F, Santer B, Zöllner E, Jürgens K, Jamieson C, Boersma M, Gocke K (2003b) Daphnia versus copepod impact on summer phytoplankton: functional compensation at both trophic levels. Oecologia 135:639-647

Sommer F, Saage A, Santer B, Hansen T, Sommer U (2005a) Linking foraging strategies of marine calanoid copepods to patterns of nitrogen stable isotope signatures in a mesocosm study. Mar Ecol Prog Ser 286:99-106

Sommer U, Hansen T, Blum O, Holzner N, Vadstein O, Stibor H (2005b) Copepod and microzooplankton grazing in mesocosms fertilised with different Si:N ratios: no overlap between food spectra and Si:N influence on zooplankton trophic level. Oecologia 142:274-283

Sterner RW, Elser JJ (2002) Ecological stoichiometry. Princeton University Press, Princeton

Straile D (2000) Meteorological forcing of plankton dynamics in a large and deep continental European lake. Oecologia $122: 44-50$
Straile D, Adrian R (2000) The North Atlantic Oscillation and plankton dynamics in two European lakes-two variations on a general theme. Global Change Biol 6:663-670

Sverdrup HU (1953) On conditions for the vernal blooming of phytoplankton. J Cons Explor Mer 18:287-295

Tilzer MM, Elbrächter M, Gieskes WW, Beese B (1986) Lighttemperature interactions in the control of photosynthesis in Antarctic phytoplankton. Polar Biol 5:105-111

Urabe J, Clasen J, Sterner RW (1997) Phosphorus limitation of Daphnia growth Is it real? Limnol Oceanogr 42:1436-1443

Utermöhl H (1958) Zur Vervollkommnung der quantitativen Phytoplankton-Methodik. Mitt Int Ver Theor Angew Limnol 9:263-272

Walther GR, Post E, Convey P, Menzel A, Parmesan C, Beebee TC, Fromentin JM, Hoegh-Guldberg O, Bairlein F (2002) Ecological responses to recent climate change. Nature 416:389-395

White HH (1979) Effects of dinoflagellate bioluminescence on the ingestion rates of herbivorous zooplankton. J Exp Mar Biol Ecol 36:217-224

Yachi S, Loreau M (1999) Biodiversity and ecosystem productivity in a fluctuating environment: the insurance hypothesis. Proc Nat Acad Sci U S A 96:1463-1468 